\title{
Apoio institucional para o fortalecimento de mulheres em contexto rural
}

\author{
Institutional support for strengthening women in rural settings \\ Maria Aparecida Alves Sobreira Carvalho ${ }^{1}$ \\ Maria Natália Bizerra Pimentel Monteiro ${ }^{2}$ \\ Carolina Marinho Marcelo ${ }^{3}$ \\ Renata Silvestre Moreno ${ }^{4}$ \\ Verônica Morais Ximenes ${ }^{5}$
}

\section{RESUMO}

Em uma cultura de resignação e submissão feminina, o contexto rural ainda contribui para a alienação, com escassez de espaços de reflexão sobre os mecanismos de opressão que atravessam a vida das mulheres. Este estudo objetiva investigar o potencial do apoio institucional como facilitador de processos de fortalecimento de mulheres em uma comunidade rural. Foram analisados 28 diários de campo, escritos no período de um ano e meio de atividades com um grupo de mulheres facilitado por extensionistas do Núcleo de Psicologia Comunitária (NUCOM) de uma universidade pública. Os diários foram analisados por meio do software Atlas ti 5.2 e organizados em dois temas: vida das mulheres e apoio institucional para o fortalecimento. As mulheres no contexto rural têm a vida marcada pela dificuldade de acesso às políticas públicas, desigualdade de gênero, longas jornadas de trabalho com pouca visibilidade e reconhecimento social, assumindo o protagonismo nos eventos religiosos e culturais da comunidade. O apoio institucional desenvolvido pelo NUCOM para facilitar o fortalecimento das mulheres esteve presente nas atividades participativas que integravam o pensamento, as sensações e a ação, favorecendo o encontro consigo, com o outro e com a comunidade, inaugurando novos espaços de fala, expressão das emoções e práticas.

Palavras-chave: Fortalecimento. Apoio institucional. Mulheres. Contexto rural. Extensão universitária.

\begin{abstract}
In a culture of female resignation and submission, the rural context still contributes to alienation, with a shortage of spaces for reflection on the mechanisms of oppression that run through women's lives. This study aims to investigate the potential of institutional support as a facilitator of women's empowerment processes in a rural community. A total of 28 field diaries were analyzed, written over a year and a half of activities with a group of women
\end{abstract}

\footnotetext{
${ }^{1}$ Doutoranda em Psicologia na Universidade Federal do Ceará, Brasil; professora do Ensino Básico, Técnico e Tecnológico no Instituto Federal de Educação, Ciência e Tecnologia da Paraíba, Brasil. (apsobreira1@hotmail.com).

2 Graduanda em Psicologia na Universidade Federal do Ceará, Brasil; bolsista PIBIC-CNPq (maria.natalia.bizerra@gmail.com).

${ }^{3}$ Graduanda em Psicologia na Universidade Federal do Ceará, Brasil; bolsista PIBIC-CNPq

(carolinamarinho987@gmail.com).

${ }^{4}$ Graduanda em Psicologia na Universidade Federal do Ceará, Brasil; membro do Núcleo de Psicologia Comunitária (NUCOM) (renatasilvestre46@gmail.com).

5 Doutora em Recursos Humanos e Organizações pela Universitat de Barcelona, Espanha, com estágio pósdoutoral na Universidade Federal do Rio Grande do Sul, Brasil; professora titular da Universidade Federal do Ceará, Brasil; coordenadora do Núcleo de Psicologia Comunitária (NUCOM) (vemorais@yahoo.com.br).
} 
facilitated by extensionists from the Community Psychology Centre (NUCOM) of a public university. The diaries were analyzed using Atlas ti 5.2 software and organized into two themes: women's lives and institutional support for strengthening. Women in the rural context have a life marked by difficulty of access to public policies, gender inequality, long working days with little visibility and social recognition, taking the lead in religious and cultural events of the community. The institutional support developed by NUCOM to facilitate women's empowerment was present in the participatory activities that integrated thought, sensations and action, favoring the encounter with themselves, with others and with the community, inaugurating new spaces of speech, expression of emotions and practices.

Keywords: Strengthening. Institutional support. Women. Rural context. University extension.

\section{INTRODUÇÃO}

O debate sobre o contexto rural é permeado pela ideia de estruturas arcaicas, marcadas pelo atraso e vulnerabilidades. Apesar dessa perspectiva restrita, o campo rural tem se configurado como um espaço de novas dinâmicas que superam modos de viver normatizados e homogêneos. Essas transformações não ocorrem de forma antagônica aos contextos urbanos, mas em interação com esses (LEITE et al., 2013). Em algumas comunidades rurais ainda prevalece a dificuldade no acesso à água, transporte, serviços públicos básicos e energia elétrica; ao mesmo tempo em que adotam costumes similares aos espaços urbanos, como a diminuição do uso de animais no transporte, crescente acesso a veículos e à internet.

Ainda que o espaço rural venha passando por processos de modernização, inseridos na visão de mundo e de sociedade do capitalismo, permanecem graves dificuldades no acesso a bens e serviços, visto que historicamente os maiores investimentos estatais estiveram voltados ao meio urbano (ALBUQUERQUE, 2001). Portanto, ao se debruçar sobre o contexto rural, é importante reconhecer suas particularidades históricas, sociais, culturais e ecológicas, distintas do campo urbano pela construção de um modo de vida baseado no uso da terra e de outros recursos naturais, identificando-o como lugar de produção de histórias de vida e de identidade (WANDERLEY, 2001).

O Censo Agropecuário do IBGE (2017) analisou o contexto rural pelas diferenças de gênero e contabilizou cerca de 15 milhões de mulheres, representando $47,5 \%$ da população brasileira habitando nesse espaço. Dos empreendimentos rurais, quase $20 \%$ são dirigidos por mulheres, embora esse percentual aumente para $70 \%$ a $80 \%$ quando os alimentos são produzidos para o autoconsumo. Apesar do aumento da participação feminina, segundo Bojanic (2017), as mulheres do contexto rural são as que sofrem mais situações de desigualdade social, política e econômica, enfrentando maiores restrições no acesso a terra, insumos agrícolas, água, 
sementes, tecnologia, ferramentas, crédito, assistência técnica, culturas rentáveis, mercados de produção e cooperativas rurais. Em termos percentuais, 30\% são donas formais de suas terras, $10 \%$ conseguem ter acesso a créditos e apenas 5\% alcançam assistência técnica, dados que marcam a desigualdade de gênero nesses territórios (BOJANIC, 2017).

Para Scott (1995, p. 75), as diferenças de classe, raça e geração perpassam a vivência feminina constituída em um determinado contexto social, pois "trata-se de uma forma de se referir às origens exclusivamente sociais das identidades subjetivas de homens e de mulheres". O gênero, segundo essa definição, "é uma categoria social imposta, sobre um corpo sexuado" (SCOTT, 1995, p. 75). Para Costa, Dimenstein e Leite (2014), embora os papéis exercidos por homens e mulheres variem entre as diferentes culturas, geralmente o masculino é mais valorizado e melhor recompensado financeiramente. Ser mulher no contexto rural traz um agravamento da desigualdade, considerando que esse espaço é marcado por relações de gênero rígidas e assimétricas (SILVA; DIMENSTEIN; DANTAS, 2018). Rígidas no sentido de seguirem o cumprimento de papéis construídos e impostos socialmente, e assimétricas no que tange à desigualdade em relação à obtenção de direitos e à divisão de tarefas, que, várias vezes, se configura de forma mais árdua para mulheres. Segundo pesquisa realizada com mulheres de um assentamento rural, Costa, Dimenstein e Leite (2014) apontam que os maiores sofrimentos se referem à pobreza, à sobrecarga de trabalho com o cuidado dos filhos e da casa e à violência de gênero, em um contexto de carência de infraestrutura e de políticas públicas.

Em uma cultura de resignação e submissão feminina, o contexto rural ainda contribui para a alienação, devido à escassez de espaços de reflexão sobre os mecanismos de opressão que atravessam os modos de vida de mulheres atuantes desse cenário. Consequentemente, o espaço rural carece da construção de espaços de apoio social capazes de gerar fortalecimento. Apoio social é reconhecido como suporte psicossocial significativo para o aumento da confiança pessoal, do bem-estar e da capacidade de enfrentamento das situações de opressão, favorecendo integração e coesão social (VALLA, 1999).

Para Silva et al. (2016), existem quatro fontes de apoio social: a família, a comunidade, a religião e as instituições. O apoio familiar é fonte de proteção, afeto, bem estar e promoção de equilíbrio emocional, aumentando a percepção de autonomia no enfrentamento das adversidades. O apoio comunitário é considerado um apoio informal que ocorre a partir de experiências e histórias partilhadas por moradores que convivem em um espaço próximo, 
enquanto o apoio religioso é mediado por uma instituição religiosa, que favorece encontros para práticas de rituais e socialização, favorecendo a integração social. E por último, destacamos o apoio institucional que é o foco desse artigo, caracterizado por Silva et al. (2016, p. 300) como um "processo interventivo no cotidiano das pessoas, realizado de modo formal, advindo de instituições diversas" como o Estado, a iniciativa privada ou a sociedade civil.

Lembramos que a perspectiva de mundo, a visão do contexto rural e do papel de gênero modelam as ações realizadas por instituições presentes nesse espaço, como as políticas públicas, as igrejas, a universidade por meio dos projetos de extensão, as Organizações NãoGovernamentais e as empresas privadas. Neste artigo, o apoio institucional está presente na atuação de um projeto de extensão de uma universidade federal que atua em uma comunidade rural de um município da Região Nordeste.

As crenças sobre o contexto rural interferem na idealização, planejamento e execução de atividades, muitas vezes assumindo uma perspectiva assistencialista, que para Macedo e Dimenstein (2009) coloca os sujeitos em condição de passividade e de recebedores de um serviço, especialmente na vida de populações à margem de direitos e garantias sociais. Essa condição pode ser modificada no apoio institucional em uma perspectiva crítica, onde as relações de assujeitamento e assimetria de poder transitam para o fortalecimento dos sujeitos. Para Montero (2003), o fortalecimento é um processo com implicações comunitárias e subjetivas, que exige um compromisso ético político. Para Carvalho, Ximenes e Bosi (2012), pressupõe experimentação e invenção de práticas marcadas pela disponibilidade, participação e relação dialógica, além de uma preocupação com os processos de exclusão.

A perspectiva de apoio institucional defendida neste artigo é o desenvolvimento do fortalecimento definido por Montero (2003, p. 72) como um processo em que "membros de uma comunidade desenvolvem conjuntamente capacidades e recursos para controlar a sua situação de vida", em um envolvimento que presume consciência crítica e participação solidária, capaz de gerar mudanças na comunidade e nos sujeitos implicados. $\mathrm{O}$ fortalecimento se constitui na experiência grupal em um contexto sócio-histórico entre pessoas que compartilham objetivos e expectativas, enfrentando os mesmos problemas (CARVALHO; XIMENES; BOSI, 2012). É um processo psicológico e ao mesmo tempo social, em que o conhecimento e a valorização de si mesmo se vinculam e dão sentido ao ser no mundo, com a "convicção de que se tem algo a dizer, de que se pode fazer algo e de que a 
ação pessoal pode ter efeito sobre o entorno" (MONTERO, 2003, p. 78). Logo, inexiste fortalecimento individual e comunitário separadamente, pois o pleno desenvolvimento de uma competência pessoal necessita da expressão em um contexto social, em função de um coletivo específico (CARVALHO; XIMENES; BOSI, 2012).

Para o desenvolvimento do apoio institucional na perspectiva do fortalecimento, destacamos as três dimensões apontadas por Carvalho, Ximenes e Bosi (2012): Valor pessoal e poder pessoal; Capacidade de refletir e agir sobre a realidade; e Sentimento de comunidade, definidos a partir do trabalho em comunidades em situação de pobreza. O valor pessoal "é um sentimento de valor intrínseco [...] sentir-se capaz de viver, gostar de si mesmo, acreditar na sua capacidade de conviver e realizar trabalho" e o poder pessoal "é a capacidade de influir na construção de relações saudáveis com os outros e com a realidade" (GÓIS, 1994, p. 52). Essa dimensão é fundamental no trabalho institucional ao reconhecer o impacto das situações de pobreza no psiquismo dos sujeitos, submetidos de forma crônica à busca da sobrevivência, relações de insegurança e negação de suas potencialidades. Nessa dimensão, o apoio institucional facilita o desenvolvimento do valor pessoal e do poder pessoal, influenciando as crenças sobre si mesmo e o reconhecimento da sua importância como sujeito, capaz de cuidar de si e influir em sistemas sociais e políticos.

A segunda dimensão do fortalecimento é a capacidade de refletir e agir sobre a realidade, em que as atividades fomentadas pelo apoio institucional devem favorecer a participação que facilite relações dialógicas, em que a consciência de si cresça junto com a consciência e o compromisso com a sua realidade que, para Freire (1983), conduz à superação da alienação que exclui e destitui os seres humanos. Quando as ações institucionais centralizam o poder, planejando e executando atividades e serviços sem a participação e o compromisso da comunidade, favorecem relações acríticas, insistindo no poder institucional para depositar informações, sem possibilidade de recriação e criatividade. É necessário que o apoio institucional tenha a sua base na crença no desenvolvimento e força da comunidade, reconhecendo as suas potencialidades e mecanismos de opressão a que estão submetidos, pois “sem esta fé nos homens o diálogo é uma farsa. Transforma-se, na melhor das hipóteses, em manipulação adocidamente paternalista" (FREIRE, 1983, p. 96).

A terceira dimensão do fortalecimento é o sentimento de comunidade, considerado por Ximenes et al. (2019, p. 3) como um "sentimento desenvolvido ao longo do tempo, mantendo-se e fortalecendo-se se a partir de relações significativas entre moradores de uma 
mesma comunidade", que se configura como estratégia de enfrentamento à pobreza rural. Para Elvas e Moniz (2010), é uma vivência que pode gerar o envolvimento com problemas e situações comuns da comunidade. Portanto, o apoio institucional não deve ter como base os grupos como um fim, mas o desenvolvimento da comunidade, seus vínculos e autonomia.

Nesse sentido, o objetivo desse trabalho é investigar o potencial do apoio institucional como facilitador de processos de fortalecimento de mulheres de uma comunidade rural.

\section{METODOLOGIA}

O método utilizado foi a pesquisa documental, inserido no âmbito da abordagem qualitativa, que possibilita a aproximação e compreensão da realidade social, indiretamente, por meio da análise de documentos produzidos pela equipe de um projeto de extensão. O presente estudo se deu a partir da análise de diários de campo, escritos no período da atuação dos/das extensionistas em um grupo de mulheres em uma comunidade rural.

Os diários de campo, como documentos secundários, ficam arquivados no Núcleo de Psicologia Comunitária (NUCOM), da Universidade Federal do Ceará, para subsidiar a supervisão da equipe de extensionista, os relatórios das atividades de extensão, a divulgação da experiência em encontros científicos e a elaboração de artigos para periódicos. Para Cellard (2008), os documentos secundários possibilitam a observação do processo de maturação das pessoas, grupos, conceitos, conhecimentos, comportamentos e práticas.

Essa pesquisa utilizou 28 diários de campo escritos no período de janeiro de 2015 a julho de 2016, durante o projeto de extensão realizado pelo NUCOM. Para Montero (2006), o diário de campo é uma técnica de pesquisa e intervenção comunitária que deve conter descrição extensa e detalhada de cada ida a campo, com informações sobre atividades desenvolvidas, metodologia utilizada, fatos ocorridos, impressões afetivas e interpretações diante da realidade. Devem relatar também alegrias, angústias, necessidades de investigação teórica e hipóteses de estudo. O diário de campo era escrito logo após a saída da equipe de extensionistas da comunidade, tornando possível o registro do maior número de detalhes observados, não só das atividades realizadas, mas de todo o processo vivenciado na interação comunitária, podendo ser escrito em linguagem coloquial. 
A atividade de extensão, caracterizada como apoio institucional, foi desenvolvida em Canafístula, distrito do município de Apuiarés, Ceará. A população total do município é de 13.925 habitantes, sendo 5.772 na zona urbana, e 8.153 na zona rural (IBGE, 2017). Desses habitantes, $50,79 \%$ são homens e $49,21 \%$, mulheres. A população é caracterizada como extremamente pobre, tendo em vista o rendimento domiciliar per capita mensal que equivale até R \$ 70,00. Da população pobre, 1.388 pessoas residem na área urbana; na área rural, são 3.085 pessoas, apresentando um Índice de Desenvolvimento Humano (IDH), no município, de 0,618 .

Na comunidade pesquisada, habitam 170 famílias, somando mais de mil pessoas que vivem com uma pequena infraestrutura constituída pela igreja, escola, posto de saúde com Equipe de Saúde da Família, duas quadras de esporte, um campo de futebol, uma creche e vários comércios de pequeno porte. A renda local provém da agricultura familiar, funcionalismo público, aposentadoria e benefícios do governo.

A inserção da equipe de extensionistas na comunidade ocorreu por meio de visitas domiciliares, atividade que continuou mobilizando e animando as mulheres para participação no grupo. Também foi uma estratégia importante para conhecimento do modo de vida das mulheres, que permitiu um contato com informações que em outras situações, como o grupo em sua formalidade, não seria possível. Na conversa no alpendre da casa ou tomando um café na cozinha, foi possível entender a ausência de algumas mulheres no grupo, as relações de gênero, a criação dos filhos, os silêncios, o contexto das falas e estratégias de enfrentamento diante das dificuldades. Para Rocha, Moreira e Boeckel (2010), a visita domiciliar é um instrumento utilizado pela Psicologia Comunitária que busca aprofundar e compreender aspectos da dinâmica familiar e comunitária, fortalecer o vínculo e a relação entre o ambiente e o comportamento das pessoas.

O grupo era composto, em média, por 10 mulheres, entre 20 e 70 anos de idade, sendo, em sua maioria, casadas, com filhos, tendo cursado até o ensino fundamental. Uma participante não era alfabetizada, o que influenciava o planejamento das atividades para favorecer a sua plena participação.

Os encontros tinham periodicidade quinzenal, com duração média de duas horas, ocorrendo na escola ou na Casa Paroquial, instituições parceiras do projeto de extensão. Ocorriam normalmente no período vespertino e ocasionalmente à noite, para algumas festividades ou 
atividades planejadas. A metodologia utilizada no grupo foi a dialógico-vivencial, constituída no encontro dialógico e afetivo pela cooperação entre extensionista e morador/a, em um movimento que se direciona à prática da libertação e desenvolvimento do sujeito comunitário (REBOUÇAS JUNIOR; XIMENES, 2010).

A equipe de extensionistas passava o final de semana na comunidade, o que possibilitava uma maior inserção e apropriação do cotidiano dos moradores e moradoras, por meio de visitas domiciliares, grupo de mulheres, filmes na praça, caminhadas comunitárias, participação na festa da padroeira e outras atividades. No início de cada semestre, existia um planejamento coletivo, onde as mulheres traziam as temáticas que mais lhes pareciam pertinentes, sendo desenvolvidas sob a forma de distintas dinâmicas participativas e vivenciais. Os temas sugeridos eram relacionados à saúde da mulher, geração de emprego e renda, lazer, violência e educação.

A equipe de extensionistas era formada por três estudantes de Psicologia que permaneciam, por um período mínimo de um ano no projeto, tempo considerado para a vinculação com a comunidade, desenvolvimento dos afetos, compromisso social e amadurecimento teóricometodológico. Além disso, considerava-se que, diante de eventuais saídas de extensionistas, ainda ficaria alguém mais experiente para facilitar a inserção dos novos integrantes da equipe na comunidade, sem comprometer o vínculo e a continuidade das atividades. $\mathrm{O}$ projeto de extensão era cadastrado na Pró-Reitoria de Extensão (PREX) da Universidade Federal do Ceará (UFC) e os estudantes possuíam bolsa para o desenvolvimento das atividades.

Os 28 diários de campo que relataram o desenvolvimento das atividades na comunidade, mediadas pelo grupo de mulheres, foram escritos manualmente, em seguida digitados, organizados e analisados por meio do software Atlas ti 5.2. A análise foi realizada por meio de uma leitura flutuante de cada diário de campo e depois organizada em dois temas: vida das mulheres e apoio institucional para o fortalecimento. Para que o segundo tema, apoio institucional para o fortalecimento, fosse mais bem desenvolvido e compreendido, foi dividido em três dimensões: valor e poder pessoal, capacidade de refletir e agir sobre a realidade e sentimento de comunidade. Os diários de campo foram identificados pelas iniciais DC, seguido pela numeração, de acordo com a sequência das idas à comunidade, preservando o anonimato das mulheres envolvidas. 


\section{RESULTADOS E DISCUSSÃO}

\section{Vida das mulheres no contexto rural}

Muitas mulheres na comunidade pesquisada são atravessadas pela dificuldade de acesso às políticas públicas de educação agravada pela desigualdade de gênero, quando "[...] a maioria delas só assina o nome [...]. Algumas dizem porque, na época delas, o acesso à educação era muito difícil, que geralmente nas pequenas comunidades as escolas só ensinavam até a quarta série e depois elas não tinham condições de irem pra outros lugares estudar" (D.C. 2).

Uma das mulheres relata a interdição nessa possibilidade de saída da comunidade, pois seu pai dizia que "[...] não queria que ela ficasse mandando bilhetes pra outros rapazes, enquanto seus irmãos aprenderam a ler e a escrever” (D.C. 2). Dentro de uma lógica patriarcal, o trabalho doméstico é estabelecido como prioridade para as mulheres. Com o casamento, o sonho de estudar permanece distante, pois seus maridos operam na mesma lógica de seus pais, na expectativa de cumprimento do papel feminino do cuidado. Sant'Anna e Penso (2017) afirmam que as vivências familiares são localizadas em cenários socioculturais específicos, tendo as suas representações simbólicas, vinculadas às escolhas presentes e posteriores de seus membros. Quando essas vivências ocorrem de forma autoritária e violenta, existe maior possibilidade de manutenção da estrutura patriarcal, produzindo um ciclo de violência que pode atravessar gerações.

As mulheres também relatam a limitação de acesso aos serviços básicos em um contexto de pobreza material: “[...] a seca, as dificuldades da falta de água e recursos materiais, chegando às vezes a precisarem de ajuda pra poderem se alimentar" (D.C. 21). No que se refere à saúde, “[...] o posto de saúde da comunidade só funciona uma vez na semana" (D.C. 5), e no caso de necessidade de realizar exames, só é possível na sede do distrito, sendo que "[...] algumas vezes elas não possuem o dinheiro da passagem" (D.C. 5).

$\mathrm{Na}$ questão ligada ao trabalho, as mulheres referiram uma diversidade de atividades “[...] de trabalho de casa até trabalho mais pesado. Cuidavam da casa, dos filhos e até do roçado, quase sempre sozinhas ou com ajuda de outras mulheres" (D.C. 15). Em uma das visitas domiciliares, uma mulher estava "[...] bordando e disse que ali era uma renda extra pra ajudar nas despesas da casa" (D.C. 3). Para Medeiros e Pinheiro (2018), as mulheres brasileiras empregam um tempo similar ao dos homens ao trabalho pago, enquanto o trabalho não 
remunerado tem um acúmulo de longas jornadas, de forma intensamente desproporcional, mesmo considerando a heterogeneidade desses grupos.

A jornada tripla de trabalhadoras mulheres foi citada em vários diários de campo, atividade reconhecida como "ajuda" aos maridos ou pais, com menor visibilidade e reconhecimento social. Quando comparado ao trabalho masculino, “[...] falaram que se sentiam cansadas, ao passo que completavam dizendo que era assim mesmo, que Deus dava força e que elas conseguiam" (D.C. 15). Reconhecer o valor das diversas atividades desenvolvidas pelas mulheres ainda é um desafio diante das situações de silêncio e invisibilidade do seu trabalho no contexto rural (SOUZA et al., 2016).

As ausências no grupo de mulheres eram justificadas: "Ela tem uma filhinha pequena e por isso às vezes fica complicado sair de casa, mas ela falou que ia fazer o possível pra poder ir no grupo" (D.C. 2). Esse contexto precisa ser levado em consideração no apoio institucional na forma de planejamento e desenvolvimento das atividades, pois "cada vez mais percebemos a presença das crianças no grupo, o que acaba por vezes distraindo um pouco as mulheres [...] Vamos pensar em uma solução pra isso, mas não podemos pedir pra que elas deixem de leválos" (D.C. 6). Caso não ocorra essa compreensão e uma intervenção para enfrentar essa situação, a mulher pode ser culpabilizada pela ausência nas atividades, sendo mais um fator de afastamento da participação comunitária.

Para Lima (2006), a falta de reconhecimento do trabalho da mulher contribui para a sua desvalorização como pessoa. Nesse sentido, o planejamento de políticas públicas precisa favorecer o protagonismo feminino, como, por exemplo, o gerenciamento da mulher sobre o gasto da renda decorrente da agricultura familiar. Esse gerenciamento articulado à dimensão de gênero ganha destaque no Programa Bolsa Família (PBF), em que 93\% dos cadastros têm as mulheres como responsáveis pelo recurso, assumindo o cumprimento das condicionalidades do programa (LEITE et al. 2016). Para Santos (2014, p. 483) é a mulher, na condição de mãe, que "executa as orientações dadas pelos programas e serviços para fortalecer os vínculos familiares e cumprir o dever parental de garantir a educação e a saúde das crianças, combatendo a reprodução da pobreza intergeracional”.

Na comunidade pesquisada, a fonte de renda fixa da maioria das mulheres "[...] era a do Bolsa Família, que era na mão delas, pois alguns maridos, quando iam receber o dinheiro, gastavam já tudo lá com bebidas e outros vícios" (D.C. 3). O gerenciamento do dinheiro pelas mulheres 
foi capaz de favorecer mudanças de impacto psicossocial, quando "[...] achavam importante (administrar o dinheiro), que antes a mulher se sujeitava a ficar com o marido por causa de comida ou uma casa e que agora não aceitavam mais isso" (D.C. 3). A produção de deslocamentos nas relações de gênero nos contextos rurais pela renda, por menor que seja, favorece processos de autonomia, podendo "impactar na participação política e operar mudanças nos sentidos produzidos pelo trabalho no meio rural” (LEITE et al., 2016, p. 52).

Mesmo diante do cansaço, outros sentidos do trabalho aparecem em uma dinâmica realizada no grupo de mulheres, na qual foi colado nas costas das participantes um papel em branco onde elas deveriam escrever uma palavra ou desenhar algo que representasse o que pensavam umas das outras: “[...] na maioria esmagadora das vezes foi 'forte' [...] Perguntamos se elas concordavam com o que outras mulheres achavam sobre elas e todas concordaram que são fortes e "trabalhadeiras"” (D.C. 11).

Um papel feminino destacado na comunidade é o gerenciamento de eventos relacionados à escola ou à igreja, principalmente a festa da padroeira. Como a comunidade tem uma tradição de muita religiosidade, as celebrações ligadas à Igreja Católica mobilizam muitas pessoas no decorrer do ano, todas lideradas pelas mulheres: "Falaram que principalmente nos festejos da comunidade elas que planejam e executam todas as atividades. Em relação às lideranças da escola e da igreja, também são compostas por mulheres" (D.C. 15). É um momento importante de visibilidade das mulheres, período rico em encontros nas praças, igreja, quadras esportivas e barracas nas ruas, onde aparece “[...] muita gente, impossível lembrar de todos os nomes, até porque algumas mulheres eram de outras comunidades" (D.C. 4). As mulheres preparam e comercializam as comidas, organizam as celebrações litúrgicas e prêmios de bingo, ornamentam e participam da festa na quadra, socializam e reafirmam aspectos de uma cultura e tradição permeada de afetos. A comunidade recebe familiares distantes e vizinhos, configurando uma comemoração importante da identidade comunitária.

\section{Apoio institucional para o fortalecimento}

Para compreender o impacto do apoio institucional desenvolvido pelo NUCOM, por meio de um projeto de extensão, analisamos os diários de campo por meio de três dimensões: valor e poder pessoal, capacidade de refletir e agir sobre a realidade e sentimento de comunidade, como destacado anteriormente. 
Na primeira dimensão do fortalecimento, o valor pessoal e poder pessoal são facilitados pela capacidade de tomar decisões autônomas, mas têm sido desqualificados socialmente na vida das mulheres porque "[...] muitas vezes o povo fala mal quando elas saem sozinhas, desacompanhadas dos filhos ou dos maridos. Algumas afirmaram não se importar com isso, outras, sim” (D.C. 20). Para Guzzo (2010), as estruturas opressoras da nossa sociedade enfraquecem as potencialidades dos indivíduos, favorecendo a alienação de si mesmo. Lembramos que o valor pessoal não pode ser associado a práticas homogêneas que exigem uma adaptação a padrões estabelecidos em um modelo único, sendo necessário um movimento de conhecimento de si e das suas relações em um caminho de tomada de consciência e autonomia (MÉLLO, 2018).

O controle social aliado à quantidade de tarefas faz com que as mulheres negligenciem o cuidado consigo: "A maioria das mulheres afirmou não ter muito tempo pra cuidar de si, alegando que os cuidados com a casa e familiares em geral já tomava muito do seu tempo [...]” (D.C. 5). Diante dessa realidade, não demonstravam necessidade de mudança ou indignação, “[...] mas de forma conformada e naturalizada, pois é como se fosse o dever delas cuidarem de tudo e de todos" (D.C. 5) e "[...] não podia parar muito pra descansar e se tratar porque se ela parasse, tudo parava também" (D.C. 10). Muitas vezes, o processo de opressão vivenciado em comunidades empobrecidas favorece o "bloqueio do potencial evolutivo ou núcleo de vida [...] realizado pelas condições psicossociais e econômicas de sobrevivência e reforçado por uma ideologia de submissão e resignação" (GÓIS, 1994, p. 32), que se apresenta como uma forma de sobrevivência para reduzir a angústia e sofrimento frente à miséria e à violência. Portanto, esse comportamento se configura também como uma possibilidade de enfrentamento que não pode ser desqualificada no apoio institucional, mas problematizada, construindo conjuntamente novas possibilidades de sentir e pensar a própria vida.

No grupo de mulheres eram facilitadas dinâmicas de grupo como forma de integrar o pensamento, as sensações e a ação, favorecendo o encontro consigo e com o outro, inaugurando novos espaços de fala e expressão das emoções: “[...] distribuímos entre elas cartões onde elas escreveriam pra mulher que estava ao lado palavras de encorajamento e apoio. Depois, pedimos pra que quem se sentisse à vontade pra ler, lesse (D.C. 23). Esse movimento também modificava a estrutura planejada pelas extensionistas: “[...] elas acabam 
conversando sobre elas mesmas, às vezes não dando muita atenção pra o assunto que a gente compartilha no grupo, o que faz muito sentido" (D.C.9).

O valor pessoal e o poder pessoal são desenvolvidos de forma processual, mediados pelo afeto, reconhecidos como "expressões da própria identidade, que se formam e se restauram nas relações sociais" (GÓIS, 1994, p. 32). Relações essas estabelecidas no debulhar junto o feijão do roçado (D.C.16), no almoço partilhado (D.C. 6), no brincar com as crianças na praça (D.C. 3; D.C. 12), na dança com as mulheres durante a festa da padroeira e na arrumação da escola depois da festa (D.C. 19). A imersão na comunidade mobilizou compromissos e sentimentos positivos: "[...] o que mais marcou a J. foi o dia em que a gente, despretensiosamente, foi jantar na casa dela. Aí eu tive a confirmação do quanto o afeto se faz necessário em trabalhos como esse" (D.C. 26).

As visitas domiciliares também funcionavam como atividade que expressava o valor das mulheres, momento de escuta e valorização, interpretado como sinal de que a equipe se importava e gostava delas: "[...] ela ficou muito grata e feliz por termos ido até lá [...] mais tarde, no grupo, quem estava lá? Ela mesma! Com um sorriso largo no rosto, feliz por estar ali, ela disse que o grupo era muito importante pra ela [...]" (D.C. 5).

O grupo facilitou o reconhecimento dos potenciais e redes de apoio: “[...] falamos sobre a possibilidade de cada uma ensinar o que sabe pra outra, como se fosse uma oficina cooperativa, onde elas trocariam alguns saberes [...], então fomos facilitando processos onde elas reconhecessem atividades que sabiam fazer" (D.C. 3).

Na segunda dimensão do fortalecimento, capacidade de refletir e agir sobre a realidade, o fatalismo foi um elemento recorrente na explicação da realidade, interferindo na reflexão e ações de mudança: “[...] mulher faz o que homem faz, mas homem não faz o que mulher faz" (D.C. 15). Ao problematizar a dificuldade de acesso aos serviços públicos básicos, as mulheres se mostraram resignadas "[...] a maioria pareceu já conformada com a situação e grata por, pelo menos uma vez na semana, haver atendimento" (D.C. 5). O fatalismo é explicado pela crença de que o destino é predeterminado e inevitável, controlado por forças externas ao sujeito, favorecendo ações de passividade, conformismo e submissão (MARTÍNBARÓ, 1998). Para Cidade et al. (2018), as populações em contexto de pobreza rural também utilizam o fatalismo como estratégia de adaptação diante das dificuldades encontradas em uma sociedade que favorece e intensifica a vivência da incerteza, do medo e da falta, portanto, 
“considerar que os fatos estão predestinados minimiza os efeitos dos sentimentos recorrentes de insegurança quanto ao futuro e de estar vulnerável aos fatos que se dão independentemente das ações tomadas pelos sujeitos" (CIDADE et al., 2018, p. 11).

Do reconhecimento dessa realidade, o apoio institucional utilizou como estratégia metodológica o círculo de cultura (D.C. 17), que, para Freire (1983), favorece a reflexão sobre os modos de vida em uma relação horizontal em que circula a palavra, proporcionando a construção de um sentido sobre o contexto sócio-histórico das opressões experimentadas no cotidiano: "Perguntei se os filhos mais velhos ou mesmo o marido não ajudavam elas nos afazeres, e ela disse que a maioria das coisas fazia sozinha" (D.C. 10); “[...] muitas falaram que os homens que dão a última palavra, com exceção de algumas. Perguntamos o porquê e elas não souberam responder” (D.C.15).

Para mediar a reflexão sobre a cultura como construção humana, mutável e atravessada por interesses e relações de poder, “[...] levamos várias imagens de artistas nordestinos [...] e começamos a conversar sobre as características da nossa cultura” (D.C. 17). O círculo de cultura foi facilitado por meio do diálogo onde não existe um detentor da palavra, e sim sujeitos que produzem e compartilham visões e concepções mediatizadas pelo mundo. Não se entrega, ou doa, nem se impõe conhecimento; se liberta e liberta-se com as pessoas (FREIRE, 1983). Dessa forma, os sujeitos podem, em conjunto, debater e problematizar as ideias, crenças e valores que manifestam as visões de mundo, reflexo direto da sua situação no mundo.

Destacamos a importância de utilizar metodologias participativas para facilitar estratégias de fortalecimento da identidade pessoal e comunitária, considerando as mulheres como sujeitos comunitários com capacidade para mudanças em sua vida e seu entorno. Nesse sentido, a participação foi fundamental desde o planejamento: “[...] conversamos sobre a importância da coletividade e falamos sobre assuntos que as mulheres gostariam que tivesse no grupo" (D.C. $1)$.

A preocupação com a didática que favorecesse a superação da educação bancária que apenas deposita informações (FREIRE, 1983) foi constante no planejamento das atividades. Na busca de superar uma relação vertical, a facilitação das atividades também tinha a implicação da história da equipe de extensionistas: "Sugerimos a construção de uma linha do tempo. 
Levamos materiais pra que cada uma construísse sua própria linha do tempo, com eventos marcantes da vida delas. Nós também construímos a nossa” (D.C. 21).

Apesar do fomento à reflexão da realidade, Souza et al. (2016) destacam que o fortalecimento das mulheres que participam da agricultura familiar é limitado pela rigidez na definição de papéis nas atividades do cotidiano e o desconhecimento das políticas públicas para a agricultura familiar, favorecendo a diminuição do seu envolvimento em atividades participativas, que poderiam provocar mudanças nesse contexto.

$\mathrm{Na}$ terceira dimensão do fortalecimento, temos o sentimento de comunidade, conceito que enfatiza "atitudes e sentimentos de uma comunidade, bem como, o relacionamento e interações entre pessoas desse mesmo contexto" (ELVAS; MONIZ, 2010, p. 452). Nesse sentido, o cuidado com os outros por meio do apoio social favorece o fortalecimento das mulheres, no sentido de dividir tarefas e possibilitar a participação em atividades fora do ambiente doméstico: “[...] elas afirmaram que sempre tentam se ajudar, seja pra emprestar alguma coisa, ou olhar o filho da outra enquanto vai resolver alguma coisa" (D.C. 5).

Apesar do reconhecimento das limitações de viver naquela comunidade, demonstravam forte sentimento de afeto ao lugar: “[...] amava morar [...] (naquela comunidade), que lá era o lugar perfeito. Disse que só não era melhor porque ali não tinha emprego, e essa mesma fala estava presente no discurso de outras mulheres" (D.C. 3). Esse sentimento de pertencimento ganhava maior proporção quando as mulheres se envolviam nas atividades comunitárias: “[...] a gente é o motor daqui. Sem a gente, tudo para. Todas as mulheres concordaram e começaram a falar sobre todas as atividades que faziam" (D.C. 15). Esse sentimento era materializado especialmente na organização da festa da padroeira e da festa junina, tradições ainda fortes no contexto rural.

O vínculo afetivo foi percebido também nas relações cotidianas: "Notei uma boa relação entre elas, que, de tão próximas, pareciam ser da mesma família. Antes e após a realização do encontro elas ficaram conversando entre si, numa partilha informal de acontecimentos das suas vidas" (D.C. 1), favorecendo a partilha dos poucos bens materiais: “[...] os filhos de todo mundo comem na casa de todo mundo, como se a comunidade fosse uma grande família" (D.C. 5). Apesar das dificuldades, as mulheres apresentaram grande sentimento de afeto pelo lugar. Em uma reflexão sobre um filme que apresentava os conflitos de uma sertaneja que migrou para uma grande cidade para enviar dinheiro à sua família, as mulheres “[...] falaram 
sobre as dificuldades de estar longe do local de origem e que nem se imaginavam nessa situação. O sentimento de pertença delas é muito forte e a maioria diz que deseja passar o resto da vida naquela comunidade" (D.C. 13). Para Ximenes et al. (2019), quanto maior a ruralidade, maior tende a ser o sentimento de comunidade, em que a proximidade física e emocional dos moradores se torna essencial para a sobrevivência, diante da pobreza e do pouco acesso às políticas públicas.

\section{CONSIDERAÇÕES FINAIS}

O objetivo desta pesquisa foi compreender o apoio institucional como facilitador de processos de fortalecimento de mulheres de uma comunidade rural. Para tal, analisamos inicialmente a questão de gênero, em que constatamos que na ruralidade as mulheres são atravessadas pela dificuldade de acesso às políticas públicas, pobreza material e trabalho excessivo, condições impostas pela legitimidade da compreensão e ação patriarcal e pelo histórico descaso estatal nesse espaço.

$\mathrm{O}$ apoio institucional ao valorizar o valor e poder pessoal redimensiona as suas atividades para o desenvolvimento comunitário sem invisibilizar as pessoas, atento ao diálogo e experiência emocional, afetando e sendo afetado pelos conteúdos problematizados. Esse processo é capaz de impactar nas possibilidades de enfrentamento de quem participa das atividades em direção à autonomia.

A segunda dimensão, a capacidade de agir e refletir na realidade, alerta as instituições para a necessidade de superar uma educação bancária que baseia ações institucionais no instrucionismo, em um poder assimétrico que desconsidera o conhecimento e a possibilidade de intervir na realidade do sujeito comunitário. O uso de metodologias participativas pode facilitar o enfrentamento do fatalismo em um horizonte de libertação.

$\mathrm{Na}$ terceira dimensão, o sentimento de comunidade, fundamenta a necessidade do apoio institucional reconhecer os costumes, crenças, sentimentos e práticas experimentadas historicamente no espaço configurado como comunidade rural. Nesse sentido, o protagonismo das mulheres ganha maior expressão nas festividades religiosas, mantendo importante aspecto da identidade comunitária de contextos rurais. 
Destacamos a importância dessas dimensões valorizadas no planejamento do apoio institucional, enxergando os nós que se enlaçam na teia comunitária, os fios que se conectam e os movimentos que produzem, reconhecendo os encontros, confrontos, opressões e possibilidades de reconfiguração à partir nas necessidades daquela comunidade específica.

Como limitação dessa pesquisa, apontamos o número pequeno de mulheres que participaram desse estudo, ao tempo em que destacamos a profundidade e extensão do vínculo estabelecido com a equipe de extensão. Ressaltamos que as instituições precisam observar as questões de gênero, problematizando a ausência ou menor envolvimento das mulheres nas atividades propostas.

Por fim, ressaltamos a necessidade de maior investimento das políticas públicas em contextos rurais, de forma específica, com mulheres, população historicamente oprimida e invisibilizada, reafirmando um apoio institucional capaz de compromisso ético, político e afetivo.

\section{REFERÊNCIAS}

ALBUQUERQUE, F. J. B. Aproximación metodológica desde la psicologia social a la investigación en las zonas rurales. Estudios Agrociales y Pesqueros, Madrid, v. 191, n. 1, p. 225-233, 2001.

BOJANIC, A. A importância das mulheres rurais no desenvolvimento sustentável do futuro. Nações Unidas Brasil, 2017. Disponível em: https://nacoesunidas.org/artigo-aimportancia-das-mulheres-rurais-no-desenvolvimento-sustentavel-do-futuro/. Acesso em: 2 dez. 2019.

CARVAlHO, M. A. A. S.; XIMENES, V. M.; BOSI, M. L. M. Processos de fortalecimento em um movimento comunitário de saúde mental no nordeste do Brasil: novos espaços para a loucura. Aletheia, Canoas, n. 37, p. 162-176, 2012.

CELLARD, A. A análise documental. In: POUPART, J. et al. (org.). A pesquisa qualitativa: enfoques epistemológicos e metodológicos. Petrópolis: Vozes, 2008. p. 295-316.

CIDADE, E. C. et al. Escala multidimensional de fatalismo: validação da versão para contextos de pobreza rural. Revista de Psicología, Santiago, v. 27, n. 2, p. 23-35, 2018.

COSTA, M. G. S.; DIMENSTEIN, M. D. B.; LEITE, J. F. Condições de vida, gênero e saúde mental entre trabalhadoras rurais assentadas. Estudos de Psicologia, Natal, v. 19, n. 2, p. 145-154, 2014. Doi: 10.1590/S1413-294X2014000200007.

ELVAS, S.; MONIZ, M. J. V. Sentimento de comunidade, qualidade e satisfação de vida. Análise Psicológica, Lisboa, v. 28, n. 3, p. 451-464, 2010. Doi: 10.14417/ap.312. 
FREIRE, P. Pedagogia do oprimido. Rio de Janeiro: Paz e Terra: 1983.

GÓIS, C. W. L. Noções de psicologia comunitária. 2. ed. Fortaleza: Edições UFC, 1994.

GUZZO, R. S. L. Da opressão à libertação: uma perspectiva urgente para a psicologia: a conclusão de um projeto, a abertura de perspectivas. In: LACERDA JUNIOR, F.; GUZZO, R. S. L. (org.). Psicologia \& Sociedade: interfaces no debate sobre a questão social. Campinas: Alínea, 2010. p. 13-18.

IBGE. Sinopse do Censo Demográfico. 2017. Disponível em:

https://www.ibge.gov.br/estatisticas/economicas/agricultura-e-pecuaria/21814-2017-censoagropecuario.html?=\&t=resultados. Acesso em: 2 dez. 2019.

LEITE, J. F. et al. A formação em psicologia para a atuação em contextos rurais. In: LEITE; J. F.; DIMENSTEIN; M. (org.). Psicologia e contextos rurais. Natal: EDUFRN, 2013. p. 2756.

LEITE, J. F. et al. Participação política e autonomia de mulheres no meio rural brasileiro. In: XIMENES, V. M. et al. (org.). Implicações psicossociais da pobreza: diversidades e resistências. Fortaleza: Expressão Gráfica e Editora, 2016. p. 45-67.

LIMA, M. S. A. As mulheres no sindicalismo rural. In: SCOTT, P.; CORDEIRO, R. (org.). Agricultura familiar e gênero: práticas, movimentos e políticas. Recife: Editora da UFPE, 2006. p. 101-126.

MACEDO, J. P.; DIMENSTEIN, M. Psicologia e a produção do cuidado no campo do bem estar social. Psicologia \& Sociedade, Natal, v. 21, n. 3, p. 293-300, 2009. Doi:

$10.1590 / \mathrm{S} 0102-71822009000300002$.

MARTÍN-BARÓ, I. Psicología de la liberación. Madrid: Trotta, 1998.

MEDEIROS, M.; PINHEIRO, L. S. Desigualdades de gênero em tempo de trabalho pago e não pago no Brasil, 2013. Sociedade e Estado, Brasília, v. 33, n. 1, p. 161-187, 2018. Doi: 10.1590/s0102-699220183301007.

MÉLLO, R. P. Cuidar? De quem? De quê? A ética que nos conduz. Curitiba: Appris, 2018.

MONTERO, M. Teoría e práctica de la psicología comunitaria: la tensión entre comunidad y sociedad. Buenos Aires: Paidós, 2003.

MONTERO, M. Hacer para transformar: el método en psicología comunitaria. Buenos Aires: Paidós, 2006.

REBOUÇAS JUNIOR, F. G; XIMENES V. M. Psicologia comunitária e psicologia históricocultural: análise e vivência da atividade comunitária pelo método dialógico-vivencial.

Pesquisas e Práticas Psicossociais, São João del-Rei, v. 5, n. 2, p. 151-162, 2010. 
ROCHA, K. B.; MOREIRA, M. C.; BOECKEL, M. G. A entrevista e a visita domiciliar na prática do psicólogo comunitário. In: SARRIERA, J. C.; SAFORCADA, E. T. (org.).

Introdução à psicologia comunitária: bases teóricas e metodológicas. Porto Alegre: Sulina, 2010. p. 205-214.

SANTOS, Y. I. G. As mulheres como pilar da construção dos programas sociais. Caderno CRH, Salvador, v. 27, n. 72, p. 479-494, 2014. Doi: 10.1590/S0103-49792014000300003.

SCOTT, J. Gênero: uma categoria útil de análise histórica. Educação e Realidade, Porto Alegre, v. 20, n. 2, p. 71-99, 1995.

SILVA, E; DIMENSTEIN, M.; DANTAS, C. Violência contra a mulher em um assentamento rural de reforma agrária do nordeste brasileiro. Revista Latino Americana de Geografia e Gênero, Ponta Grossa, v. 9, n. 1, p. 88-106, 2018. Doi: 10.5212/Rlagg.v.9.i1.0005.

SILVA, L. B. et al. Apoio social como modo de enfrentamento à pobreza. In: XIMENES, V. M. et. al. (org.). Implicações psicossociais da pobreza: diversidades e resistências. Fortaleza: Expressão Gráfica e Editora, 2016. p. 289-310.

SOUZA, K. B. et al. Empoderamento das agriculturas integrantes da rede Mãos à Horta, Rio Pomba/MG. Revista Ciência em Extensão, São Paulo, v. 12, n. 4, p. 98-112, 2016.

WANDERLEY, M. N. B. A ruralidade no brasil moderno: por um pacto social pelo desenvolvimento rural. In: GIARRACCA, N. (org.). ¿Una nueva ruralidad en América Latina? Buenos Aires: Consejo Latinoamericano de Ciencias Sociales, 2001. p. 31-44.

VALLA, V. V. Educação popular, saúde comunitária e apoio social numa conjuntura de globalização. Cadernos de Saúde Pública, Rio de Janeiro, v. 15, Sup. 2, p. 7-14, 1999. Doi: 10.1590/S0102-311X1999000600002.

XIMENES, V. M. et al. Sentimento de comunidade e pobreza rural no nordeste, norte e sul do Brasil. Subjetividades, Fortaleza, v. 19, n. 1, p. 1-13, 2019. Doi:

10.5020/23590777.rs.v19i1.e7923.

Submetido em 21 de agosto de 2020.

Aprovado em 17 de setembro de 2020.

Em Extensão, Uberlândia, v. 19, n. 2, p. 24-42, jul.-dez. 2020. 